http://jmscr.igmpublication.org/home/

ISSN (e)-2347-176x ISSN (p) 2455-0450

crossref DOI: https://dx.doi.org/10.18535/jmscr/v7i11.39

\title{
Lithium Toxicity Causing Neuroleptic Malignant Syndrome
}

\author{
Authors \\ Uthaya Sankar M.K ${ }^{1}$, Naveen Sathish.V ${ }^{2}$, Sibi Chakravarthy. $C^{3}$ \\ ${ }^{1}$ Professor, ${ }^{2,3}$ Post Graduate Residents \\ Department of General Medicine, Sri Manakula Vinayagar Medical College and Hospital, \\ Puducherry-605107, India
}

\begin{abstract}
Lithium is used as a mood stabiliser. Here we report a case of bipolar disorder on Lithium and Olanzapine presented with fever, generalised rigidity and unconsciousness. He was diagnosed as Neuroleptic malignant syndrome (NMS). His serum lithium level was elevated. Lithium associated NMS usually occurs only in combination with antipsychotics at around 0.01-3\%.
\end{abstract}

\section{Introduction}

Neuroleptic malignant syndrome (NMS) is a lifethreatening neurologic emergency associated with the use of antipsychotic (neuroleptic) agents and characterized by a distinctive clinical syndrome of mental status change, rigidity, fever, and dysautonomia. Incidence rates for NMS range from 0.02 to 3 percent among patients taking antipsychotic agents. NMS is mostly found associated with the use of traditional antipsychotics, but may also occur when atypical antipsychotics such as risperidone, olanzapine, and clozapine are used ${ }^{1}$.

There are some cases of NMS associated with the use of non-neuroleptic drugs, like carbamazepine and metoclopramide,or drugs without known anti-dopaminergic activity, such as lithium. Lithium is a first-line mood stabilizer used in the treatment and prophylaxis of bipolar disorder. There are several case reports of lithiumassociated NMS, but only in combination with antipsychotics $^{2}$.

\section{Case Report}

A 54 year male presented to casualty in unconscious state with history of fever for past four days after which he developed generalised rigidity and altered sensorium. No other positive history. He was an old case of bipolar disorder and was on lithium and olanzapine for past 20 years. On examination his GCS was $5 / 15$ with a raised heart rate of $120 / \mathrm{min}$, blood pressure of $160 / 100 \mathrm{~mm} \mathrm{Hg}$ and a temperature of $104^{\circ} \mathrm{F}$ and oxygen saturation of $85 \%$. Systemic examination showed bibasal coarse crepititions and a rigid tone of all four limbs. Blood investigations showed elevated total count and renal profile and elevated creatine kinase. Chest x-ray showed features of aspiration pneumonia. Neuroimaging showed no abnormality. He was diagnosed as Neuroleptic Malignant Syndrome and aspiration Pneumonia. Due to poor GCS he was intubated and mechanically ventilated. The reason for his NMS was evaluated and his serum Lithium level was elevated at $4.3 \mathrm{meq} / \mathrm{L}$. Lithium was discontinued. $\mathrm{He}$ was treated with intravenous antibiotics, 
supportive care and hemodialysis. Patient sensorium improved after dialysis and he was extubated on the second day. He was discharged with valproate after psychiatry consultation. At the time of discharge his serum lithium came to normal at $1.08 \mathrm{meq} / 1$.

\section{Discussion}

Lithium is a alkali used in bipolar disorder as mood stabiliser mainly for mania. It has a narrow therapeutic range of $0.95-1.5 \mathrm{mEq} / \mathrm{L}^{3}$. It causes depletion of phosphatidylinol bisphosphate and impairs the ability of neuron to respond to a neurotransmitter ${ }^{3}$. Though lithium is used as an mood stabiliser not all patients develop NMS. NMS with Lithium therapy has mostly been noted in patients who are on antipsychotic therapy. Isolated lithium associated NMS is very rare. Certain conditions are required for a patient on lithium therapy to develop NMS such as acute infection, vomiting, dehydration, reduced renal clearance $^{3}$. Toxicity symptoms varies from mild diarrhea, vomiting, fatigue, tachycardia, hyperthermia, tremor, uncontrollable movements, muscle weakness, drowsiness to coma, seizure, acute kidney injury ${ }^{1}$. For treatment of toxicity commonly used agents are benzodiazepines, dantrolene, bromocriptine, amantadine. These drugs are more likely to be used in severe cases and if the patient worsens ${ }^{1}$.

\section{Conclusion}

Care has to be taken in patients with lithium therapy regarding NMS and serum lithium level has to be assessed regularly.

\section{References}

1. Patil V, Gupta R, Verma R, Balhara YPS. Neuroleptic malignant syndrome associated with lithium toxicity. Oman Med J. 2016 jul;31:4.
2. Pope HG, Cole JO, Choras PT, Fulwiler CE. Apparent neuroleptic malignant syndrome with clozapine and lithium. Journal of Nervous and Mental Disease. 1986 Aug.

3. Keck PE, Pope HG, Cohen BM, McElroy SL, Nierenberg AA. Risk factors for neuroleptic malignant syndrome: a casecontrol study. Archives of General Psychiatry. 1989 Oct 1;46(10):914-8. 